\title{
Paying for informed consent
}

Akira Akabayashi and Michael D Fetters Kyoto University, Kyoto, Fapan and University of Michigan Health System, Ann Arbor, Michigan, USA

\begin{abstract}
The Fapanese Ministry of Health and Welfare has implemented a policy of paying physicians to explain the nature of the patient's medical condition and the treatment plan. We describe the precepts of this policy and examine ethical dimensions of this development. We question whether this policy will be sufficient to ensure patients will have the opportunity to become informed participants in medical decision making. The policy also raises a broader philosophical question as to whether informed consent is a fundamental ethical requirement of all doctor-patient encounters or an option that can be exercised by physicians for financial gain. The impact of this policy in Fapan merits continued observation from abroad.

(Fournal of Medical Ethics 2000;26:212-214)
\end{abstract}

Keywords: Informed consent; Japan; reimbursement; health insurance

\section{Introduction}

Japan has implemented a policy that remunerates physicians for explaining the nature of the patient's medical condition and the treatment plan at the time of hospital admission. In essence, it is a policy of paying physicians for implementing informed consent. Since April 1, 1996, physicians have been permitted to charge the national health insurance system for explaining the treatment plan in writing to the patient. The charge is called Nyuuin Chiryou Keikaku Kasan, literally, "Additional Fee for the Treatment Plan at Admission". With the exceptions of charges for care of the elderly and hospice/palliative care, Japanese physicians are paid on a fee-for-service basis with uniform, itemised price-setting by the Ministry of Health and Welfare (MHW). Under this new policy, the hospital director can charge the national health insurance for hospital physicians who have provided this procedure at the time of the patient's admission to the hospital.

Issued on March 8, 1996, Ministry of Health and Welfare public notification (kokuji) No 21 states that if the physician explains the treatment plan, the patient's disease, and the planned period of hospitalisation in a written document to the patient at the time of admission, the physician can bill for 200 points (equal to $¥ 2,000$ : $\$ 16.7$ or $£ 11.8$ [ $\$ 1$ to $¥ 120, £ 1$ to $¥ 170]) .{ }^{1}$ Ministry of Health and Welfare notification (kacho tsuchi) No 21 that was released on the same day provides more details. It states that the diagnosis or disease condition and planned period of hospitalisation should be explained directly to the patient. In circumstances when full disclosure of the diagnosis is not appropriate given the patient's future treatment, partial disclosure is permissible and must be documented on the chart. This exception was necessary because most Japanese physicians make a decision about whether to disclose a serious diagnosis to the patient on a case-by-case basis. For patients who cannot understand an explanation (such as infants or comatose patients), the fee cannot be requested. Notification No 21 directs physicians to meet these requirements within seven days of admission in accordance with a written format illustrated in the notification appendix. It requires documentation of the attending physician(s) and chief nurse, the admitting diagnosis and other possible diagnoses, and the planned period of hospitalisation. Finally, it requires the patient to sign the document used by the physician to explain this information. The physician's signature is not required.

In 1997 the MHW revised the initial policy. Ministry of Health and Welfare public notification No 26, which was issued on March 14, raised the fee from $¥ 2,000$ to $¥ 3,500$, and specifically prescribed that the explanation process should be done in cooperation between physicians and related professionals, including nurses. ${ }^{2}$ Ministry of Health and Welfare notification (kacho tsuchi) No 29, which was issued on the same day, clarified the new procedural changes: 1 ) the treatment plan should be made in cooperation with physicians, nurses, and related professionals; 2) the diagnosis, the disease condition, the treatment plan, the content and schedule of physical examination and surgery, and the planned period of stay should be explained by the physician, and 3) in the case of a patient who cannot understand the explanation, the fee can be requested if the information is explained to the family. Two phrases from notification No 21, 1996, namely, "in the case of 
patients who could not understand the explanation, the fee could not be requested" and "the documents used for explanation should be signed by the patient", were deleted. Instead, the form in notification No 29 requires the physician's signature at the bottom. Since the document is given to the patient, the patient's signature is not required. The second version of the form emphasises the physician giving information to the patient, and does not require a symbolic signature of consent by the patient.

In addition to the charge at admission, there is also a fee, called the Discharge Guidance Fee, (Taiin Shidoryo) that is worth $¥ 3,000$ and assessed at the time of discharge, for informing the patient and/or the patient's family about the postdischarge treatment plan and issues that require attention after discharge. This process must also be documented using a standardised form that is signed by the physician and placed in the patient's file.

As of April 1999, official statistics on the use of this new inpatient charge were not available. However, there is evidence that the policy has influenced Japan's health care expenditures. As of May 1996, the two main national health insurance bodies (Seifu Kansho Hoken and Kokumin Kenko Hoken), which hold about $65 \%$ of total health insurance in Japan, had received 143,316 requests for payment and had paid out about $¥ 286,631,800$ /month ( $\$ 238,860$ or $£ 168,607)$ (estimated value, personal communication with a MHW officer, November 19, 1998). In one month in 1998, one 900-bed hospital in Tokyo had requested payment for 530 of 810 (65\%) admissions, charges totaling $¥ 1,855,000$. Though only a fraction of total health care expenditures, these data indicate that paying for informed consent has at least caused a ripple in Japan's health care economics.

\section{Discussion}

To our knowledge, this health care policy that pays for the process of informed consent is the first in the world. Though the policy does not explicitly require all the criteria of informed consent as defined in medical ethics, the elements required for reimbursement by this policy are essential but not necessarily sufficient for implementing informed consent. While physicians can be reimbursed for time communicating with patients in many places in the world, this policy clearly provides an incentive to include necessary elements of informed consent. Indeed, it may be the first approximation of a medical ethics procedure to be recognised to be of such importance that the physician who obtains consent is remunerated for the time spent with the patient. It is an encouraging development as it acknowledges that providing information to patients and families, and involving them in decision making is symbolically as important as doing medical procedures or providing other medical consultations. Policy-makers and insurers need to take notice of the value that is being attributed to communication about illness in the doctor-patient relationship.

\section{Clinical suspicions}

Still, contextual aspects of the Japanese health care system are sufficiently compelling to raise cynical suspicions. First, a physician's explanation of the patient's medical condition and the treatment plans may conceivably lack even the most basic elements of informed consent, ${ }^{3}$ yet still qualify to receive the fee. The minimum requirement to qualify for payment is completion of the explanation form at the time of admission. There is a risk that completion of the form will become an end rather than a means for ensuring sufficient patient understanding and opportunity for participation in decision making.

Second, another risk is that the policy will increase the burden on nurses in an already hectic clinical setting. While Ministry of Health and Welfare notification No 29 requires physicians to provide this information to patients and their families, nurses are involved in the whole process. Nurses may be required to do most of the job while physicians only take a few minutes with the patient and the family. Physicians completing forms and handing them to patients without any dialogue is a conceivable worst case scenario.

Third, are Japanese physicians so driven by profit that financial incentives are the only mechanism for sufficiently motivating them to engage patients in informed consent discussions? It can be argued that informed consent is such a fundamental component of medical care that it should be included in every encounter, and not billed separately. Indeed, it can be argued that informed consent should be an integral part of every doctor-patient decision. A separate charge might be construed as meaning that explaining the nature of the illness and treatment and obtaining the patient's informed consent is optional.

As in many countries, patient trust of doctors has been decreasing in Japan. By paying for time spent explaining medical information to the patient and engaging the patient in treatment planning, this policy clearly has two potential benefits for doctors. It provides an opportunity to benefit financially for time spent communicating with the patient and an opportunity to nurture anew the faltering doctor-patient relationship. 
The onus now is upon Japanese physicians to prove themselves worthy of remuneration for time spent with the patient to communicate in accordance with the precepts of the informed consent doctrine about the patient's illness and treatment options. Failure to meet the new expectations may result in revocation of the remuneration scheme, and the physicians themselves paying in terms of lost earnings, and for the missed opportunity to nurture the trusting doctor-patient relationship. There are plans to conduct cost-benefit analyses of this programme, though how they will be conducted is unclear at this time.

\section{Conclusion}

The financial incentive to explain relevant medical information and the treatment plan while providing the patient with an opportunity to refuse participation amounts to a policy of paying for informed consent. This policy alone is unlikely to ensure an adequate informed consent process in Japan, though it may help facilitate greater expec- tations of patient participation in medical decision making. The impact of this policy in Japan merits continued observation from abroad. The success of this programme in Japan may herald a precedent that validates remunerating physicians for the time required to ensure patients' informed consent. There are lessons to be learned from this novel approach, regardless of the outcomes.

Akira Akabayashi, MD, PhD, is Professor, Department of Biomedical Ethics, School of Public Health, Kyoto University Graduate School of Medicine, Kyoto, Fapan. Michael D Fetters, MD, MPH, MA, is Director of the Fapanese Family Health Program, Department of Family Medicine, University of Michigan Health System, Ann Arbor, Michigan, USA.

\section{References}

1 Official gazette (Kampo) 1996 No 50, Mar 8.

2 Official gazette (Kampo) 1997 No 48, Mar 14

3 Faden RR, Beauchamp TL. A history and theory of informed consent. Oxford: Oxford University Press, 1986.

\section{News and notes \\ Journal of Medical Ethics - http://www.jmedethics.com}

Visitors to the world wide web can now access the Fournal of Medical Ethics either through the BMJ Publishing Group's home page (http:/ www.bmjpg.com) or directly by using its individual URL (http://www.jmedethics.com). There they will find the following:

- Current contents list for the journal

- Contents lists of previous issues

- Members of the editorial board

- Subscribers' information

- Instructions for authors

- Details of reprint services.
A hotlink gives access to:

- BMJ Publishing Group home page

- British Medical Association website

- Online books catalogue

- BMJ Publishing Group books.

The web site is at a preliminary stage and there are plans to develop it into a more sophisticated site. Suggestions from visitors about features they would like to see are welcomed. They can be left via the opening page of the BMJ Publishing Group site or, alternatively, via the journal page, through "about this site". 